\title{
Author Correction: Regenerative medicine and injection therapies in stress urinary incontinence
}

\author{
Christopher J. Hillary, Sabiniano Roman, Sheila MacNeil, Wilhelm K. Aicher, Arnulf Stenzl and Christopher R. Chapple
}

Nature Reviews Urology (2020) https://doi.org/10.1038/s41585-019-0273-4 Published online 23 January 2020

The originally published article contained errors in the section "Muscle-derived stem cells". In the original text "In another study, which included 33 patients, a large biopsy of skeletal muscle $(5-30 \mathrm{~g})$ was needed to obtain a usable amount of MDSCs, which was associated with donor site pain, bruising and bleeding ${ }^{64}$. Patients demonstrated significant improvements in pad weight testing following MDSC injection therapy $(P<0.001)$." the described patient numbers, biopsy weight, adverse events and $P$ values were incorrect. The text has been corrected to "In another study, which included 38 patients, skeletal muscle biopsy was associated with biopsy site pain and/or bruising ( 3 of 38 patients) ${ }^{64}$. Patients demonstrated significant improvements in pad weight testing following MDSC injection therapy $(P<0.01)$." The changes have been made in the html and PDF versions of the article.

https://doi.org/10.1038/s41585-020-0340-x I Published online 26 May 2020

(c) Springer Nature Limited 2020 